Portland State University

PDXScholar

$5-18-1984$

\title{
Effects of Intraperitoneal and Intracerebral Injections of Triiodothyronine on Temperature Selection in Fish
}

Dennis A. Grahn

Portland State University

Follow this and additional works at: https://pdxscholar.library.pdx.edu/open_access_etds

Part of the Animal Sciences Commons, and the Biology Commons Let us know how access to this document benefits you.

Recommended Citation

Grahn, Dennis A., "Effects of Intraperitoneal and Intracerebral Injections of Triiodothyronine on Temperature Selection in Fish" (1984). Dissertations and Theses. Paper 3294.

https://doi.org/10.15760/etd.3285

This Thesis is brought to you for free and open access. It has been accepted for inclusion in Dissertations and Theses by an authorized administrator of PDXScholar. Please contact us if we can make this document more accessible: pdxscholar@pdx.edu. 
AN ABSTRACT OF THE THESIS OF Dennis A. Grahn for the Masters of Science in Biology presented May 18, 1984.

Title: Effects of Intraperitoneal and Intracerebral Injections of Triodothyronine on Temperature Selection in Fish.

APPROVED BY MEMBERS OF THE THESIS COMMITTEE:

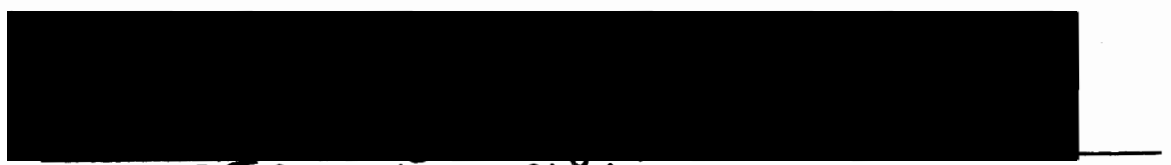

Larry I Crawshaw, Chăirman

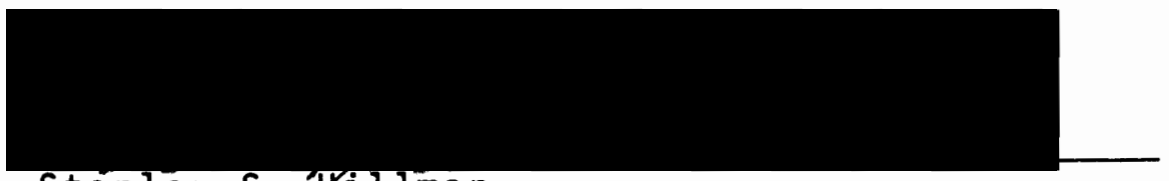

Stanley S. Hillman

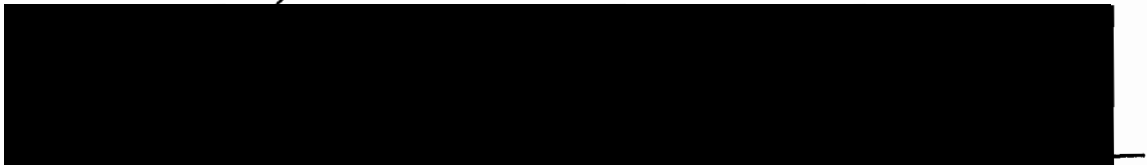

Malcolm S. Lea

Goldfish (Carassius auratus) of $15-28 \mathrm{~g}$ were maintained at $23 \mathrm{C}$ and subsequently were intraperitoneally injected with saline (controls) and varying doses of Triodothyronine $\left(T_{3}\right)$. Following the injection, the fish were placed in a thermal gradient and temperature selection and activity 
monitored for $30 \mathrm{~min}$. There was no significant difference between the responses of the experimental fish to the different doses of $T_{3}$. However, there was a significant difference in response between the experimental and control groups $(P<0.001)$. The decreased temperature selection occurred early in the test runs, while the increased activity began later. Larger goldfish (175-205g) recieved $0.5 \mu 1$ intracerebral injections of $1.5-3.0 \mathrm{ng} \mathrm{T}_{3}$ in the anterior brainstem via an indwelling cannula injection system. These fish responded to the injections by selecting cooler water. The magnitude of the response was related to the distance of the injection site from the preoptic/anterior hypothalamic region. I conclude that increased plasma levels of $\mathrm{T}_{3}$ lead to the selection of cooler water. This effect appeared to be mediated via the anterior brainstem. Injected $T_{3}$ also produced hyperactivity. This latter effect developed more slowly and appeared to be more diffusely mediated. 


\title{
EFFECTS OF INTRAPERITONEAL AND INTRACEREBRAL
} INJECTIONS OF TRIIODOTHYRONINE ON TEMPERATURE SELECTION IN FISH

by

DENNIS A. GRAHN

\begin{abstract}
A thesis submitted in partial fulfillment of the requirements for the degree of
\end{abstract}

MASTER OF SCIENCE in

BIOLOGY

Portland State University 
TO THE OFFICE OF GRADUATE STUDIES AND RESEARCH:

The members of the committee approve the thesis of Dennis A. Grahn presented May 18, 1984.

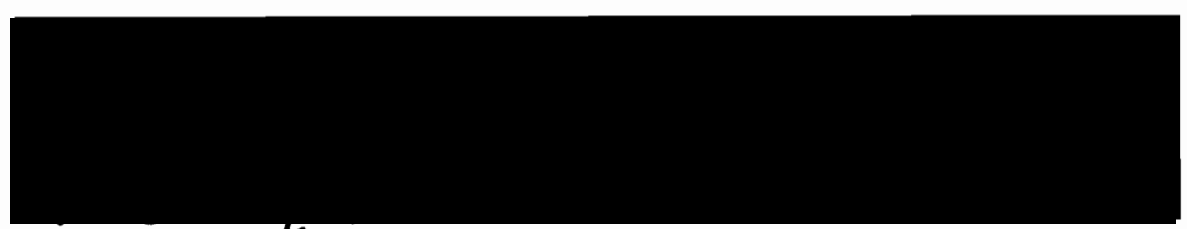

Larry I Krawshaw

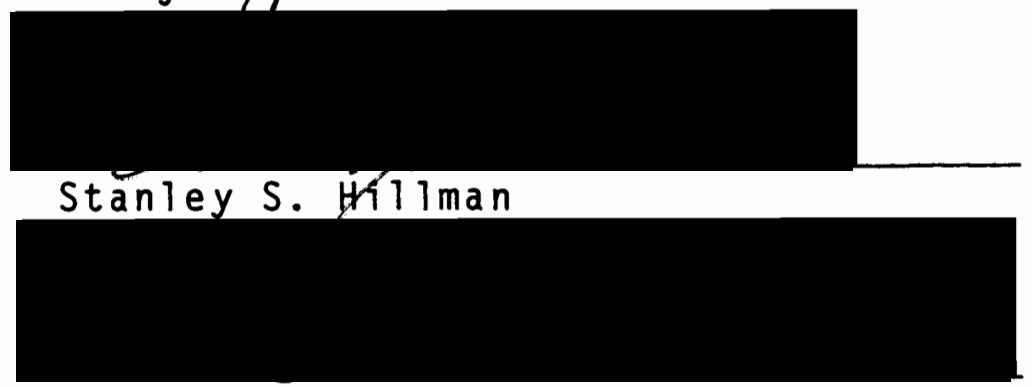

Malcolm S. Lea

W. Herman Taylor, Head, Degartment of Biology

Stanley EF. Rauch, Dean of Graduate Studies and Research 


\section{ACKNOWLEDGEMENT}

Dr. Larry Crawshaw's support and guidance is greatly appreciated. However, Marvis Fraiser was a very poor selection for a role model. A very large debt of gratitude is still owed the Lonergan family without whom I never would have survived. 
TABLE OF CONTENTS

PAGE

ACKNOWLEDGEMENT. • . . . . . . . . . . . . . . . . . .

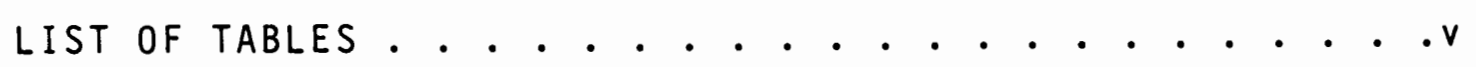
LIST OF FIGURES. • • • • • • • • • • • • • • • • • • • vi INTRODUCTION • • . . . . . . . . . . . . . . . . . . . 1 MATERIALS AND METHODS. . . . . . . . . . . . . . . . 11 RESULTS. . . . . . . . . . . . . . . . . 15 DISCUSSION . . . . . . . . . . . . . . . . 22 REFERENCES . . . . . . . . . . . . . . . . . . 27 


\section{LIST OF TABLE}

TABLE

PAGE

I DOSE, SELECTED TEMPERATURE, ACTIVITY AND

INTEGRATED RESPONSE FOR INTRAPERITONEALLY

INJECTED CONTROL AND EXPERIMENTAL FISH.

VALUES ARE MEANS AND STANDARD ERROR OF

THE MEAN. . . . . . . . . . . . . . . . 19 
1. Mean selected temperature and mean activity vs. time for 5 fish injected intraperitoneally with $0.01 \mathrm{ng} \mathrm{T}_{3} / \mathrm{g}$ body mass and 21 controls. . . .17

2. Mean selected temperature of 7 experimental $(n=5)$ and control groups of fish. All fish were injected with $1 \mu 1 / \mathrm{g}$ body mass $\mathrm{T}_{3}$ solution. . . 18

3. Selected temperature and activity vs. time for a $205 \mathrm{~g} \mathrm{goldfish}$ injected with $0.5 \mu 1$ of 0.008 ng $T_{3} / g$ body mass directly into the preoptic/anterior hypothalamic region. . . . . . 20

4. Integrated response $\left({ }^{\circ} \mathrm{C} \cdot \mathrm{min}\right.$ spent below the preinjection average) vs. distance of injection site from the preoptic/anterior hypothalamic region(PO/AH). Six fish were injected 3 times. .21 


\section{INTRODUCTION}

Ectotherms are animals whose temperature is primarily determined by that of the environment. Ectotherms are often referred to as poikilotherms because their body temperature varies over a wide range. The ability to function with different body temperatures requires that poikilotherms adapt their internal systems to these altered thermal environments. Such adaptations occur at all levels of organization from molecular rearrangement to complex individual and social behavioral responses.

Adaptive responses, which permit activity over a large environmental temperature range, are limited by the animal's genotype. Resistance adaptations allow for a temporary extension of normal thermal limitations. Exceeding the resistance boundaries results in death for an animal. The causes of death at high or low temperatures are multiple. Measurement of the high and low lethal temperature characterizes a zone of tolerance for a species. The zone of tolerance of aquatic ectotherms changes with thermal acclimation.

Capacity adaptations, which allow normal activity over varying thermal ranges, result from cold or warm acclimation 
or environmental acclimitization. This paper is concerned with capacity adaptations of goldfish (Carassius auratus). These adaptations involve physiological, biochemical, structural and behavioral changes (1).

Thermal adaptations take place on organ system, cellular and subcellular levels. Cellular acclimation to a new temperature is not accomplished by a few simple biochemical changes; rather it is the net outcome of a complex reorganization of subcellular metabolic processes involving the interplay of many mechanisms. Contributing responses include the change in concentration of enzymes or isozymes, changes in modulators (phospholipids and allosteric activators and inhibitors), rerouting of the carbon flow (through the glycolytic pathway, the tri-carboxylic acid (TCA) cycle, the pentosephosphate shunt and other anabolic and catabolic pathways), and changes in membrane permeability and composition (2).

For a poikilotherm's cellular metabolic mechanisms to function optimally at varied temperatures the above changes must occur in most subcellular organelles. The changing of metabolic substrates for different acclimation states is an example. The glycolytic pathway occurs in the cell cytoplasm, while the TCA cycle enzymes are located in the matrix of the mitochondria, and the oxidative phosphorylation machinery is an intergal part of the mitochondrial inner membrane. The outer membrane of the 
mitochondrion is fairly permeable to small molecules and ions. The inner mitochondrial membrane is more like the plasma membrane in that it is very impermeable to small molecules and ions. For the TCA cycle to function molecules must pass through a transport system in the inner mitochondrial membrane. In fish, winter mitochondrial respiration is driven more effectively by substrates that are different from those that drive mitochondrial respiration in summer. It is speculated that the differences in respiration rates are caused by differences in the rate of substrate transport across the mitochondrial membranes (3).

Coincidental with fluxes of environmental temperature, significant changes in the fluidity of the lipid bilayer of poikilotherms biological membranes have been observed (4). These changes in the physical properties of the membrane have been shown to have a major effect on many basic cell functions including the rates of substrate oxidation, ATP production and the activity of membrane bound enzymes and associated mechanisms (5). Many poikilotherms are able to compensate by changing the chemical composition of the lipid portions of the membranes ( 6$)$, and in this way maintain the proper fluidity of the membranes at different temperatures. The characteristic changes in membrane composition during exposure to decreased temperature are an increase in longer and more unsaturated membrane lipid fatty acids ( 7 ). 
Each species has a well defined region of temperature in which it functions optimally. At extremes thermophilic bacteria grow and reproduce in hot springs at $85 \mathrm{C}$, while Antarctic fishes inhabit $-1.8 \mathrm{C}$ sea water. Among the adaptations of the thermophilic bacteria are an increased thermostability of their t-RNA through increases in guanosine-cytosine base pair content and increased disulfide bridging of proteins (8). The icefish possess the ability to produce a glycoprotein antifreeze which allows the fish to function below the freezing point of its tissue as predicted by the colligative properties of these tissues (9)

Within the temperatures available, different vertebrates select varying thermal environments depending on their genotype and current physiological needs. Poikilotherms typically select a narrow range of temperature appropriate to their physiological requirements. For poikilothermic vertebrates to be able to rapidly and accurately select a specific temperature they must have a central nervous mechanism specifically for temperature regulation. The functions of the basic components must include sensing the temperature of the body, signalling when the body is above or below its optimal temperature and activating appropriate responses $(10)$.

The localization of the thermoregulatory centers in fish has occurred within the last 15 years and followed from 
earlier work done on mammals. In the late 1800's and early $1900^{\prime}$ s the importance of the anterior portion of the mammalian brain stem both in sensing internal temperature and in integrating thermal input was established (11). In the $1940^{\prime} \mathrm{s}$ it became clear that in mammals the most important integrative neuronal circuts for temperature regulation were located in the hypothalamus (12). In 1969, Myhre and Hammel showed that reptiles possess both anterior brainstem and peripheral thermosensetivity which interact to determine thermoregulatory behavior (13). Crawshaw and Hammel (14) demonstrated the importance of the anterior portion of the brain stem in thermoregulation in brown bullheads. By heating or cooling a small area of the hypothalamic region with chronically implanted thermodes, the fish were caused to swim into cooler or warmer water respectively. Later, Nelson and Prosser demonstrated that lesions in the anterior hypothalamic region of the brain stem caused green sunfish and goldfish to loose their ability to select temperature in a thermal gradient (15). Neurons in the outer skin of bony fish are very sensitive to temperature, responding to changes of considerably less than one degree $C$. However, to evoke a thermoregulatory response greater changes are necessary (16). Thus, Antarctic icefish acclimated to $3 \mathrm{C}$ were quiescent in the $3 \mathrm{C}$ water but rapidly moved from the $5 \mathrm{C}$ water into the $3 \mathrm{C}$ water when placed in the warmer water. 
This rapid response occurred too soon for a change to occur in the brain or body core temperature (17).

Neurophysiological recordings from the peripheral temperature sensitive neurons of mammals, birds, reptiles and amphibians show a response to rapid shifts in temperature with a sudden burst of impulses. Similar neurons are likely found in fish, since behavioral experiments indicate they can detect small, rapid shifts in temperature (18). The phasic nature of the input makes it unlikely that these sensors are the sole imput for thermoregulation (2). Stable regulation also requires a deep core temperature sensor.

Given the above system to direct a fish to water of a particular temperature, an organism can benefit from selection of different temperatures during varied physiological states. For instance, during starvation some salmonids select cooler water which presumably decreases metabolic demands on a poikilothermic organism (19). Conversely, when there is an abundance of food it would be advantagous to select warmer water to optimize growth. These changes in selected temperature could be mediated by adjustment of neuronal activity, hormonal levels or other inputs. Fish regulate their temperature with regard to their recent thermal environment, their physiological state, their current metabolic needs, and the thermal environments 
available to them. Of major importance is their state of thermal acclimation (14).

Little work has been done to elucidate acclimational changes at the level of the organ system in the intact animal. In most cases the mechanisms and significance of alterations in regulated body temperature are not well understood, as, for instance the effect of thermal acclimation on temperature selection in fish.

One way to evaluate the time course of acclimation is to determine the temperature selected by an ectotherm placed in a thermal gradient. Brown bullheads (Ictalurus nebulosus) maintained at 25 C for a period of 7 days when placed in a gradient almost immediately moved to a preferred temperature of 29-31 C. However, fish maintained at $7 \mathrm{C}$ when placed in a gradient immediately moved to 14-16 C and within $2 \mathrm{~h}$ to $22 \mathrm{C}$, following which they slowly migrated toward their final preferendum. The time required to reach their final thermal preferendum was about $20 \mathrm{~h}(20)$. The time required for bullheads to reach the final thermal preferendum is dependant on the acclimation temperature and the time spent at that temperature $(20)$.

$$
\text { As noted by Prosser and Nelson }(p .283,2) \text {, "neither }
$$

the neuronal mechanism for change in preferred temperature with time in a gradient nor the time course of acclimation for preferred temperature is known". There are many possible explanations for the way acclimation affects the 
selected temperature in fish; included are effects due to maliase (the reaction to generalized physiological stress resulting from thermally induced disturbances such as acid-base balance and oxygen demands), a direct cellular acclimation effect on individual neurons and a hormonally mediated effect.

The malaise hypothesis is that the organization of the thermoregulatory centers of the brain of aquatic ectotherms remains unaltered by thermal acclimation. Thus, a constant error signal would be present, serving to draw the cold acclimated animals in a gradient into warmer water. Excessively rapid movement into warmer water would be prevented by the sensing of physiological stress induced by difficulties in $\mathrm{O}_{2}$ uptake, acid-base regulation or other imbalances (21). However, Crawshaw (22) has observed that cold acclimated brown bullheads exposed to low ( 80 torr) and normal ( 160 torr) $\mathrm{P}_{2}$ in the gradient moved to warmer water at similar rates. Crawshaw et al (23) have also shown that neither $\mathrm{O}_{2}$ uptake nor acid-base imbalance exert an appreciable influence on the movement of cold acclimated large mouth bass (Micropertus salmoides) into warmer water. A second hypothesis is that there is a direct cellular acclimation effect on individual neurons, and requires a differential subcellular acclimation by two populations of hypothalamic neurons. Studies on cellular acclimation have shown that alterations include the restructuring of protein, 
carbohydrate and lipid components of the cell populations. This involves nuclear regulation which occurs over a period of weeks. Some acclimation effects are observed after hours or days at a new temperature. The discrepancy in the time required for cellular acclimation to occur and the time in which the behavioral responses occur makes this hypothesis unlikely as a total explanation (16).

I chose to test the third hypothesis: that thermal acclimation affects temperature selection through a direct hormonal effect on the thermoregulatory neurons, thus protecting aquatic ectotherms from excessively rapid movement into too warm water. A possible mechanism is that receptors of the hypothalamic thermoregulatory neurons might bind a substance that increases during cold acclimation.

Studies using mammals show that increased levels of thyroxine $\left(T_{L_{4}}\right)$ or triiodothyronine $\left(T_{3}\right)$ cause similar responses on a cellular basis as the effect of cold acclimation on poikilotherms (24). Studies with fishes are many but the general consensus of reviewers is that thyroid hormones ( $\mathrm{T}_{4}$ and $\mathrm{T}_{3}$ ) cause many subcellular changes that vary depending on species and the animal's previous environmental and physiological state $(25,26)$.

It is well. documented that increases in $T_{4}$ and $T_{3}$ induce hyperactivity in mammals (24) and in fish (26). Less well appreciated is thyroid hormones role in temperature regulation. It has been shown that altered thyroid activity 
affects the body temperature of homeotherms (27), and that altered thyroid activity is important during the entrance into the state of torpor in hibernating mammals (27). The role of thyroid hormones in temperature selection in poikilotherms is poorly understood.

Fortune (28) placed $0.5 \mathrm{~g} / 1$ of thiourea (an inhibitor of thyroxine formation) in the water of Phoxinus phoxinus for four weeks, after which the fish selected warmer water than the controls. Reynolds, Casterlin and Spieder (29) obtained similar results with goldfish, and in addition found that for both goldfish and bluegill, maintaining 20 $\mu \mathrm{g} / \mathrm{l}$ of thyroxine in the water for 1 day or two weeks decreased the temperature selected by $2 \mathrm{C}$ and $10 \mathrm{C}$ respectively. Crawshaw et al (30) have demonstrated that plasma $T_{3}$ levels increase in bullheads with acclimation to colder water.

The hypothesis to be tested is that one function of the thyroxine system in fish is to mediate the selection of cooler water in cold acclimated fish. This hypothesis will be tested by the injection of $T_{3}$ both intraperitoneally (IP) and intracerebrally (IC). 
MATERIALS AND METHODS

The study utilized small (15-28 g) and large (175-205 g) goldfish (Carassius auratus) obtained from a commercial fish farm. The fish were observed in a 9 channel temperature gradient. Each channel was $23 \mathrm{~cm}$ wide, $244 \mathrm{~cm}$ long and $16 \mathrm{~cm}$ deep. Attached to each end were heat exchangers coupled by circulating pumps to either a hot or a cold source. The $244 \mathrm{~cm}$ length was divided into 10 equal areas by baffles and each area was vigorously aerated. After $2 \mathrm{~h}$ of running, a stable linear thermal gradient was established in each channel. For these studies each gradient ranged from about 7 to 36 C. Continuous monitoring showed that any point in the gradient was stable to within $0.4 \mathrm{C}$ for the duration of the experiment. The temperature of each area of each gradient was measured before and after each experimental run with a copper-constantan thermocouple and recorded on a strip chart recorder.

The position of the fish in the gradient was continuously monitored by a low light wide angle camera-video cassette recorder (V.C.R.) time lapse recorder system with a real time clock readout on the screen. After the actual experiments, the tapes were played back and the position of the fish in the gradient was manually entered into an Apple 2 e computer. The position data (taken at $5 \mathrm{~s}$ intervals) and the temperature recordings of each gradient, 
provided an accurate record of the animals temperature selection and activity.

In the first set of experiments, 16 small goldfish (15-28 g) were selected and maintained inside the laboratory for 6 days at $25 \mathrm{C}$. The fish were then distributed in the gradients which contained $25 \mathrm{C}$ water. The gradients were then turned on. The fish were habituated for $8 \mathrm{~h}$ and returned to their holding tank. The following morning 8 of the 16 goldfish were placed in the gradient for three $h$. Within 5 min of being placed in the gradient the fish were calm and spent most of the time at their preferred temperature. All 8 fish were removed from the gradients, placed in $500 \mathrm{ml}$ plastic beakers, weighed and returned (in the beaker) to the gradient. Each hour, for the next $7 \mathrm{~h}$, the fish were removed from the gradient, injected intraperitoneally with carrier solution or $T_{3}$ solution ( 1 $\mu 1 / \mathrm{g}$ body mass) and returned to the gradient. The fish in lanes 1-5 recieved doses of $T_{3}$ that increased with each successive injection. The fish in lanes 6-8 recieved only carrier solution. The concentrations of $T_{3}$ used were 0.01 , $0.02,0.04,0.08,0.16,0.32$, and $0.64 \mathrm{ng} / \mathrm{g}$ body mass. A

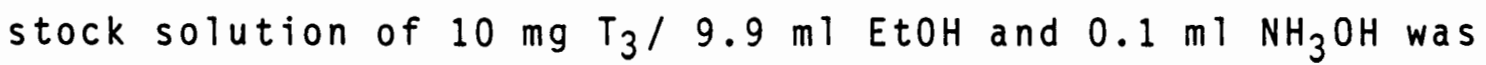
stored at $-4 \mathrm{C}$. The stock $T_{3}$ solution was diluted in $0.9 \%$ $\mathrm{NaCl}$ solution to the injection concentrations. The solution injected into the control animals was the same as the 
experimental doses, but lacked $T_{3}$. The behavior of the fish was recorded for the 25 min following the injections.

The data, recorded at $5 \mathrm{~s}$ intervals, were condensed into $30 \mathrm{~s}$ average values and plotted against time. The data from the 21 control fish ( 3 fish from 7 experimental runs) were very similar and therefore all the runs were averaged at each time interval. The data from each run of the 5 experimental fish were also averaged at each time interval. To better illustrate the effect of the experimental manipulation, the experimental average data was subtracted from the control average data at each point and summed over 25 min. This procedure produced a single number which reflected the effect of the drug on each fish.

The intracerebral injection studies used 6 large goldfish (175-205 g). They were maintained at $25 \mathrm{C}$ for 6 days and habituated to the gradient for $8 \mathrm{~h}$. Next, each fish was anesthesized in an MS-222 (tricane methane sulfonate) solution and, utilizing a stereotaxic device modified as described by Peter and Gill (31), was fitted with an indwelling cannula and cap. The cannula was secured to the fish's skull with mandibular bone screws and dental acrylic.

This system allowed us to repeatedly inject $0.5 \mu 1$ solutions into specific regions of the brain. By utilizing landmarks on the surface of the fish's skull and knowing the orientation of the brain to these landmarks, I was 
successful in localizing the injection sites to the hypothalamic region in $25 \%$ of the operations.

The fish were allowed to recover for $48 \mathrm{~h}$ at $25 \mathrm{C}$. They were then placed in the gradient for $2 \mathrm{~h}$ after which they were placed in flexible webbed plastic corrals located at their selected temperature and left for $30 \mathrm{~min}$. The fish were then taken from the gradient and the caps of the cannula removed and replaced with injection stylettes attached by P.E. tubing to a $10 \mu l$ syringe. The fish were replaced in the corrals and left for $10 \mathrm{~min}$, after which the appropriate solution was injected. The P.E. tubing was sealed and cut with hot forceps allowing the fish to swim free. The injection solution contained $0.004,0.008$, and $0.016 \mathrm{ng} \mathrm{T}_{3} / \mathrm{g}$ body mass on successive experimental runs. The $15 \mathrm{~min}$ prior to corraling the fish and the $30 \mathrm{~min}$ following the injection were recorded on V.C.R. tapes.

After the 3 experimental runs, the fish was injected with 0.2 ul Evans blue dye through the IC cannula, cerebrally dislocated and the brain dissected. The brain was embedded in nutrient agar, frozen and mounted on the stage of a freezing microtome. The brain was sliced to locate the dye marker. The sections containing the dye marks were photographed and compared with the stereotaxic atlas of Peter and Gill (32).

For the intracerebrally injected fish, the 5 s interval data was also condensed to a $30 \mathrm{~s}$ average selected 
temperature and plotted against time. The preinjection data from the IC injected fish served as control values. In each run the temperature at each data point for the $10 \mathrm{~min}$ preinjection period was averaged. The data points from the first 10 min postinjection was subtracted from the average preinjection value. The difference at each data point was summed. This summed difference was considered to represent the magnitude of the response to the injection. The results for each IC cannulated fish were compared to the distance of the injection site from the preoptic/anterior hypothalamic region.

To determine the activity of the fish, in both the intraperitoneal and intracerebral injection studies, the difference in temperature between successive data points was determined. This difference reflected movement of the fish within the gradient and thus is a measure of activity. Activity was analysed in a manner similar to the selected temperature data.

RESULTS

The average selected temperature vs. time and the average activity vs. time are plotted in Figure 1 for the control fish and the experimental group intraperitoneally injected with $0.01 \mathrm{ng} \mathrm{T}_{3} / \mathrm{g}$ body mass. In Figure 2 , the 
mean average selected temperature for the first $25 \mathrm{~min}$ of the seven experimental IP injection runs and the controls are compared. Table 1 lists the mean selected temperature, summed deviation from the control values and the summed activity for control and the seven experimental groups of the intraperitoneal injection study. An analysis of varience showed there was no significant difference between the results of the seven experimental runs $(F=0.535$; df $=$ $34 ; P>0.2)$. This result was unexpected and indicated the doses were too high to produce a dose response curve. Therefore, the results from the 7 experimental runs were combined and compared with the control results. A t-test between the results of the total experimental data and the control data showed significance for selected temperature $(t=15.0 ; d f=54 ; P<0.001)$, activity $(t=12.87 ; d f=54 ; P<$ $0.001)$ and the integrated response $(t=4.99 ; d f=54 ; P<$ $0.001)$.

The selected temperature vs. time and activity vs time are illustrated in Figure 3 for a fish with the injection site located directly within the anterior hypothalamic/preoptic area. In Figure 4 the integrated value of the 10 min postinjection response is compared to the distance from the preoptic/anterior hypothalamic region of the injection site for the six fish. An exponential function provided a better fit to the data in figure 4 than a linear or a power function. The best fitting equation was 

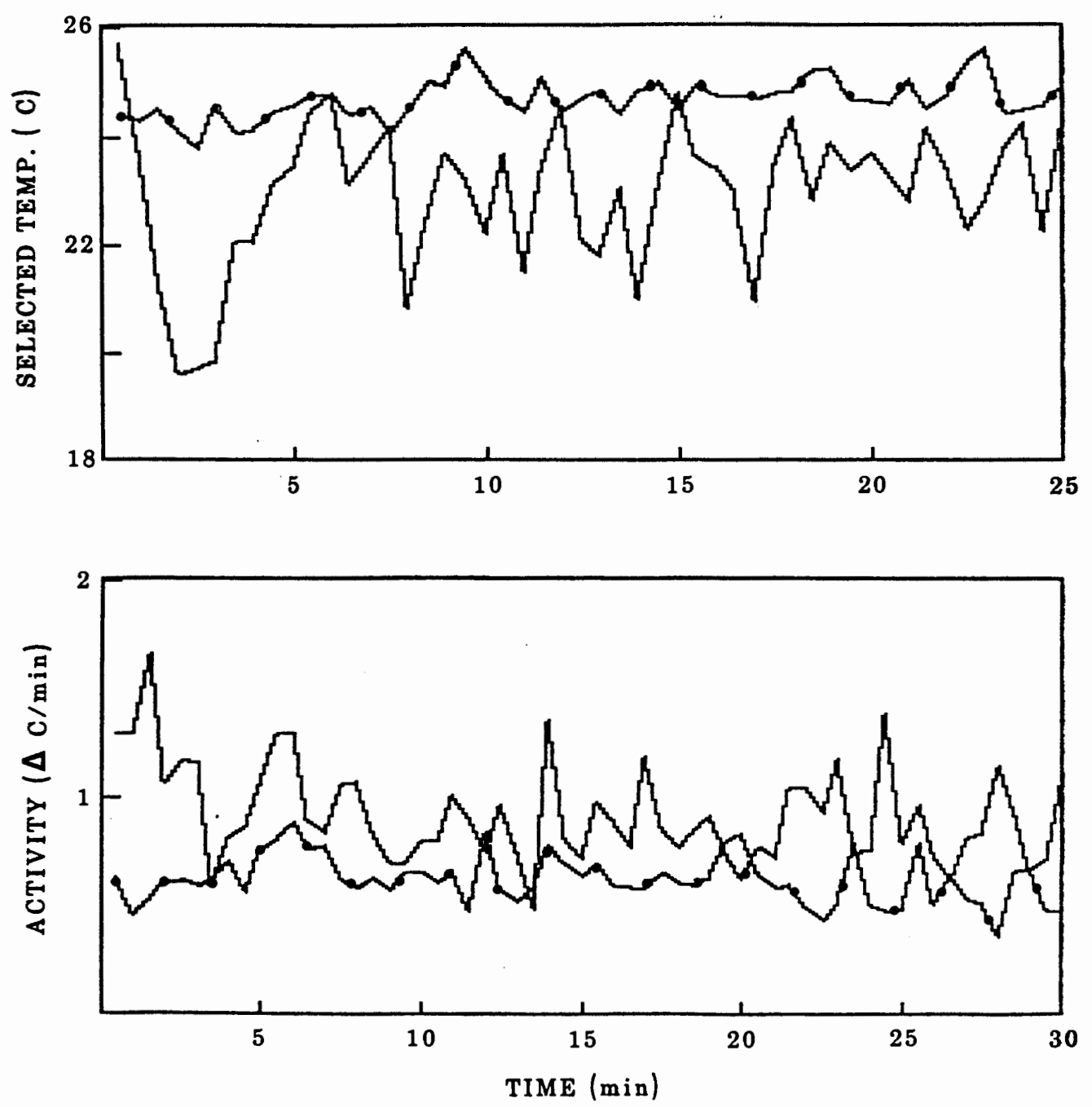

Figure 1. Mean selected temperature and mean activity vs. time for 5 fish injected intraperitoneally with $0.01 \mathrm{ngT}_{3} / \mathrm{g}$ body mass (-) and 21 controls (־..-) . 


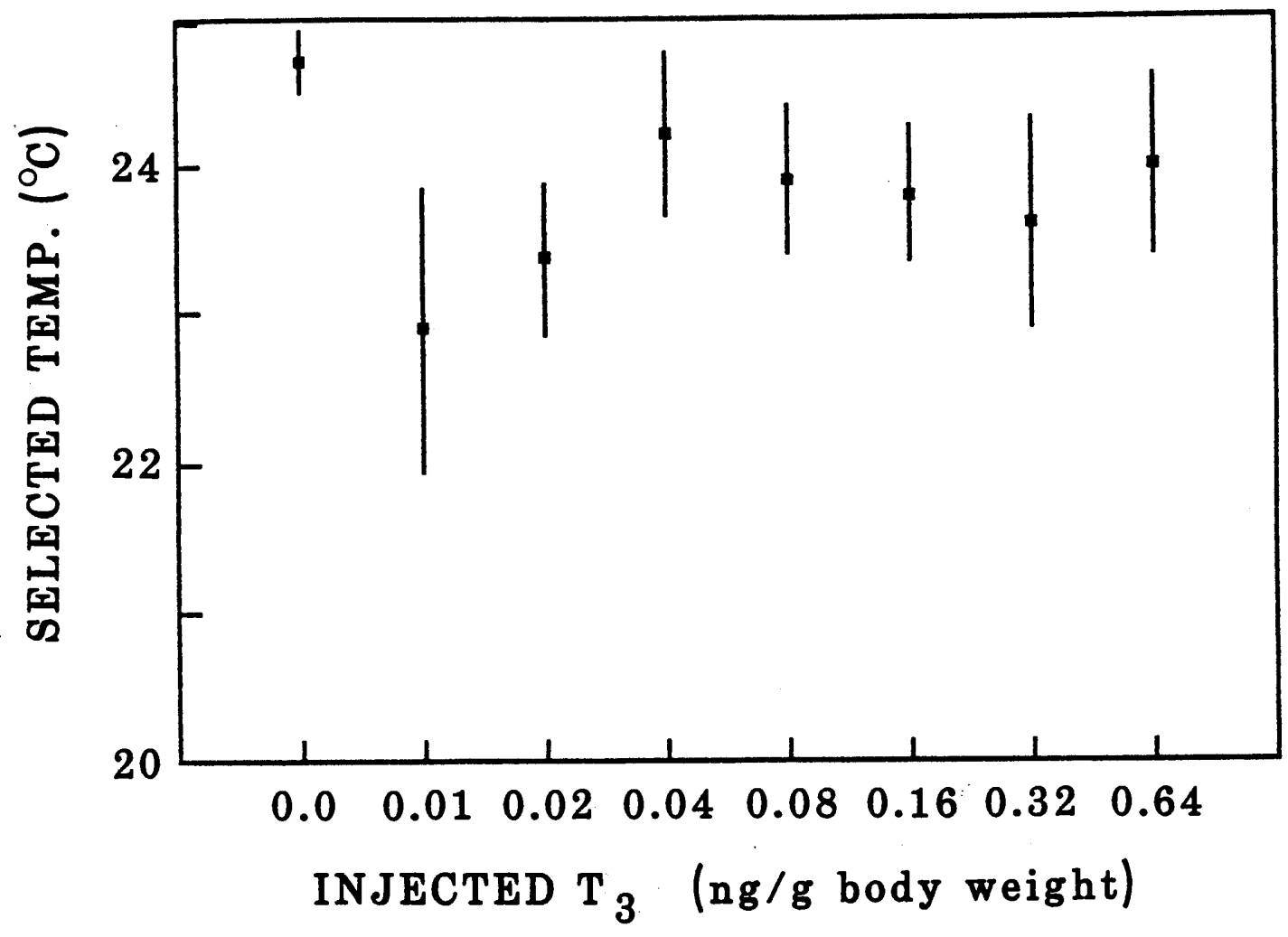

Figure 2. Mean selected temperature of 7 experimental

$(n=5)$ and 1 control groups of fish. All fish were injected with $1 \mu 1 / g$ body mass $\mathrm{T}_{3}$ solution. 
TABLE 1

DOSE, SELECTED TEMPERATURE, ACTIVITY AND INTEGRATED RESPONSE FOR INTRAPERITONEALLY INJECTED CONTROL a AND EXPERIMENTALb FISH. VALUES ARE MEANS AND STANDARD ERROR OF THE MEAN.

\begin{tabular}{|c|c|c|c|}
\hline DOSEC & SELECTED & ACTIVITYe & INTEGRATED \\
\hline & TEMPERATURE ${ }^{d}$ & & RESPONSE ${ }^{f}$ \\
\hline 0.0 & $24.7 \pm 0.2$ & $0.74 \pm 0.04$ & 0.0 \\
\hline 0.01 & $22.9 \pm 1.0$ & $0.91 \pm 0.27$ & $-85.0 \pm 47.0$ \\
\hline 0.02 & $23.4 \pm 0.5$ & $0.93 \pm 0.24$ & $-64.4 \pm 26.8$ \\
\hline 0.04 & $24.2 \pm 0.5$ & $0.99 \pm 0.25$ & $-25.8 \pm 26.6$ \\
\hline 0.08 & $23.9 \pm 0.5$ & $0.93 \pm 0.19$ & $-36.7 \pm 24.4$ \\
\hline 0.16 & $23.8 \pm 0.4$ & $0.85 \pm 0.18$ & $-43.2 \pm 22.8$ \\
\hline 0.32 & $23.6 \pm 0.7$ & $0.84 \pm 0.21$ & $-54.1 \pm 34.9$ \\
\hline 0.64 & $24.0 \pm 0.6$ & $0.66 \pm 0.20$ & $-36.4 \pm 29.4$ \\
\hline TOTALg & $23.7 \pm 0.2$ & $0.87 \pm 0.07$ & $-50.6 \pm 10.5$ \\
\hline
\end{tabular}
a - 3 fish injected 7 times each
b - 5 fish injected with successively higher doses
c - ng $T_{3} / g$ body mass
$d-{ }^{O} C$
e - change in ${ }^{\circ} \mathrm{C} / \mathrm{min}$
$f-{ }^{\circ} \mathrm{C} \cdot \mathrm{min}$ below control average temperature
$g$ - total response of all experimental fish. 


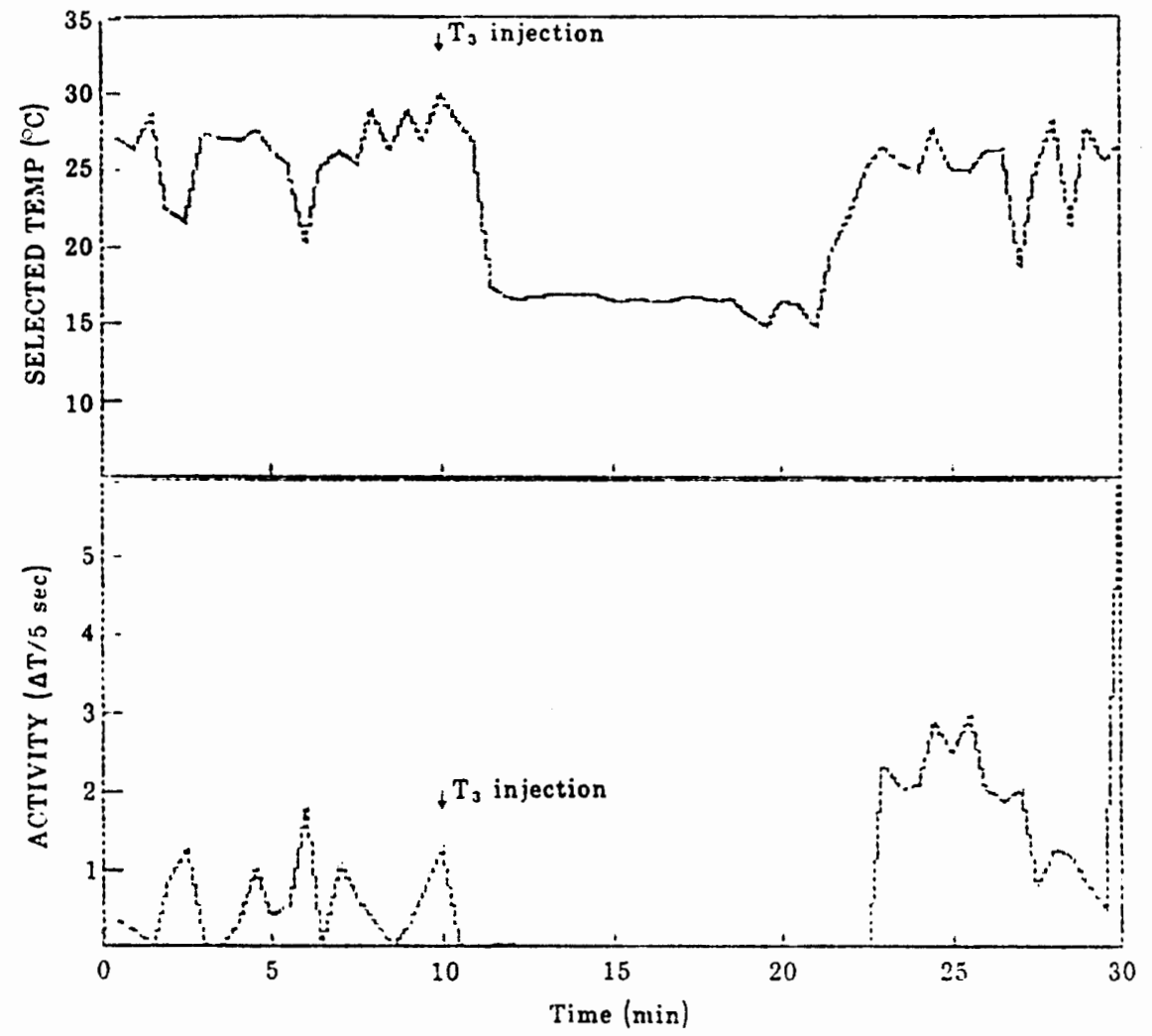

Figure 3. Selected temperature and activity vs. time for a $205 \mathrm{~g}$ goldfish injected with $0.5 \mu 1$ of 0.008 ng $T_{3} / g$ body mass directly into the preoptic/anterior hypothalamic region. 


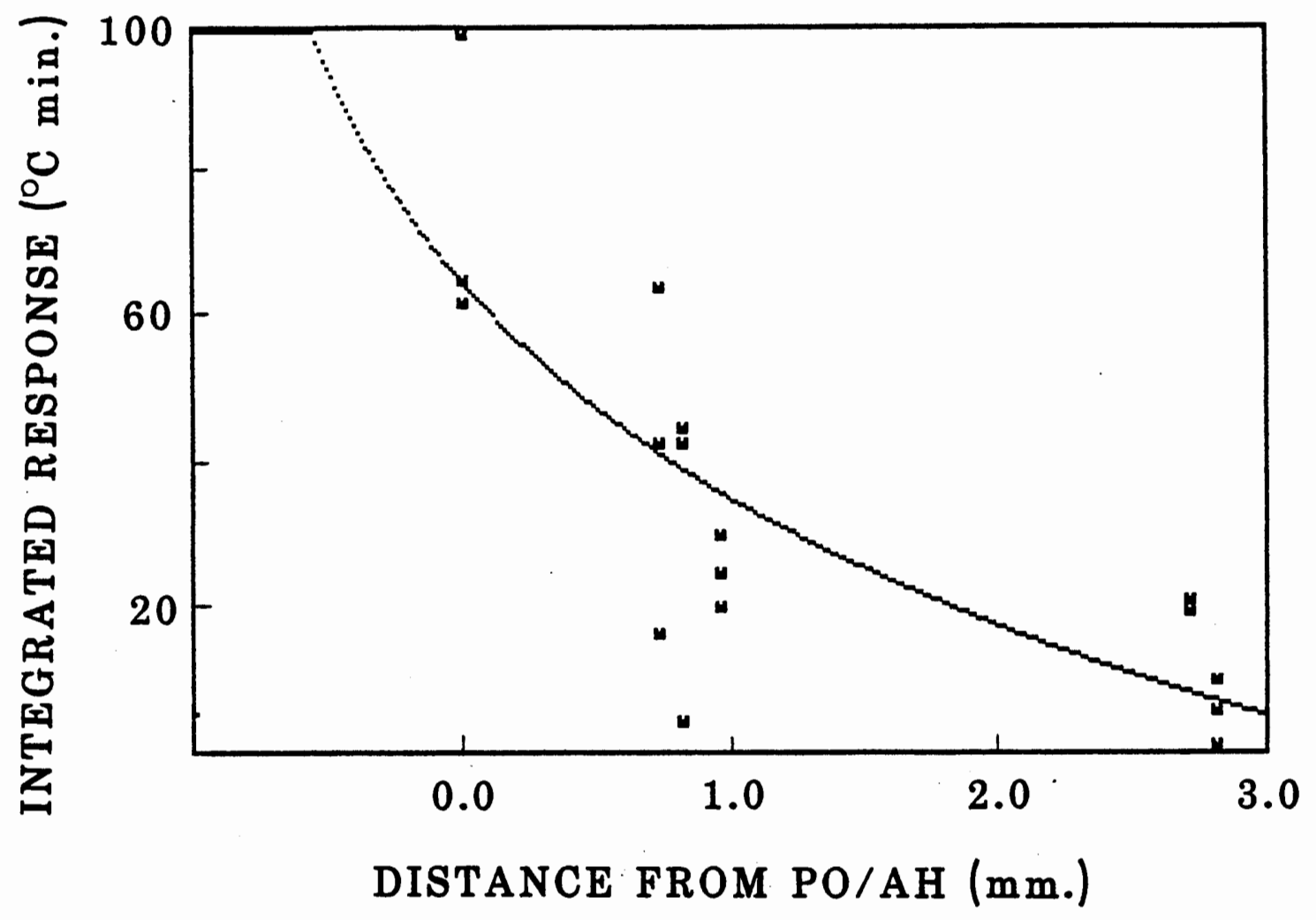

Figure 4. Integrated response ( ${ }^{\circ} \mathrm{C} \cdot \mathrm{min}$ spent below the preinjection average) vs. distance of injection site from the preoptic/anterior hypothalamic region(PO/AH). Six fish were injected 3 times. 
$Y=4.345-1.747 \ln X(r=0.673 ; d f=16 ; P<0.005)$.

\section{DISCUSSION}

This study confirms the common observation (26) that an increase in circulating plasma $T_{3}$ concentration causes an increase in the locomotor activity of fish. This increased locomotor response has been documented in salmon, trout, goldfish, cod, mudskipper, eel and trout $(26,27)$. In addition this study has shown that low levels of circulating $T_{3}$ cause a decrease in the temperature selected by goldfish.

Fortune (28) placed Phoxinus phoxinus in thiourea, a potent inhibitor of thyroxine formation, $(0.5 \mathrm{~g} / 1)$ or aerated water at $20 \mathrm{C}$ and $12 \mathrm{C}$ for 4 weeks. Following this period he monitored their temperature selection by placing them in a thermal gradient and recording their positions. Position indicated thermal selection and the rate of change of position gave an indication of activity. He found that fish treated with thiourea were more sensitive to disturbances and in general moved in short erratic bursts: He also found that the control fish selected cooler water than the thiourea treated fish. This indicates that a decrease in thyroid hormone concentration leads to selection of warmer water or that a certain concentration of thyroid hormone is necessary for normal thermoregulation. Further, 
he showed that the thiourea treated fish were more active than the controls in colder water. However, an increase in the water temperature increased the mobility of the controls, but had no effect on the activity of the treated animals. He suggested that changes in thyroid activity were correlated with changes in swimming behavior which then lead to variations in selected temperature.

Reynolds et. al. (29), utilizing an aquatic shuttle box, showed that acute exposure to thyroxine $(20 \mu \mathrm{g} / 1$ during the experiment) lowered the prefered temperature of bluegill sunfish by 2 C and goldfish by 2.1 C relative to controls. They also showed that chronic exposure to thyroxine $(20 \mathrm{\mu g} / \mathrm{l}$ for 14 days) lowered the selected temperature of bluegill by $10 \mathrm{C}$ and goldfish by $7.7 \mathrm{C}$. In contrast, chronic thiourea treated goldfish selected a temperature $2.6 \mathrm{C}$ above the controls. They questioned whether the thermoregulatory effect was induced by thyroxine $\left(T_{4}\right)$ directly or indirectly by the metabolic derivitive triodothyronine (T3). They further suggested that $\mathrm{T}_{4}$ or $\mathrm{T}_{3}$ may act directly on the synaptic membranes in the thermoregulatory centers of the central nervous system, but were unsure of the meaning of the results.

This study confirms the observations that $T_{3}$ can affect temperature selection in fish. The intraperitoneal (IP) injections produced results similar to those produced by acute $\mathrm{T}_{4}$ exposure (29). However, since our results were 
obtained by injecting $T_{3}$ directly into the fish, it is difficult to compare the results on a dose related basis.

The results from the intracerebral (IC) injection study demonstrate a high probability that $T_{3}$ is acting directly on the thermoregulatory centers of the anterior hypothalamic region. There was a significant positive correlation between the magnitude of the hypothermic response and the proximity of the injection site to the preoptic/anterior hypothalamic area. This suggests that the responses from the injections of $T_{3}$ from the various sites within the brain are correlated with the amount of injected substance that diffused into the anterior hypothalamic region.

The mechanism in fish which decreases the selected temperature in cold acclimated fish is poorly understood. The response, however, is clearly adaptive, since the preferred temperature of warm acclimated goldfish (approximately 26 C) is lethal for fish acclimated to very cold temperatures.

I suspect $T_{3}$ is involved in the mechanism to lower the selected temperature of cold acclimated fish. In a study utilizing bullheads (30), it was found that plasma $T_{3}$ increased with decreasing acclimation temperature. No change was seen in the plasma $\mathrm{T}_{4}$ levels.

Stevens (32) has speculated that, in the vertebrate subphylum, thyroxine, the $\mathrm{Na}^{+}$pump and cold are related functionally and phylogenetically. He argues that thyroxine 
increases the chill resistance in fish and causes an increase in the amount of spontaneous activity, thus increasing $\mathrm{O}_{2}$ demand. The increase in $\mathrm{O}_{2}$ demand is satisfied by increased gill ventalation. This results in increased ion exchange through the gills, which, in turn stimulates of the $\mathrm{Na}^{+}$pump. This excitement metabolism in fishes may be analogous to the non-shivering thermogenesis in mammals. Therefore, this mechanism may have been selected for as one of the main effectors in the evolution of heat production.

Eales (26) proposes that in mammals "the regulation of BMR (Basal Metabolic Rate) proceeds on a broad front and involves a wide spectrum of intracellular changes. These appear to involve not only nuclear receptor sites which may be associated with 'long term' regulation of protein synthesis, but also with 'short term' changes and regulation of $\mathrm{Na}^{+}$activity. In the early evolution of homeothermy it can be surmised that the thyroid hormones $\left(\mathrm{T}_{3}\right.$ ?) ...acquired the ability to stimulate the BMR and raise the activity of the animal beyond that expected of a true poikilotherm." (p.396, 26). Therefore, it seems likely that thyroid hormones were the initial metabolic regulators:

Eales (26) suggests that in fish the fundamental role of the thyroid is to regulate the anabolic and energy demanding activities (growth, metamorphosis and reproduction) and keep them within the abilities of the 
individual to carry them out. I feel that in addition to these activities, the thyroid also has a primary role (as suggested by Stevens, 32) in cold acclimation. I speculate that fish utilized this relationship by developing specific $T_{3}$ receptors on some of the thermosensitive neurons in the anterior hypothalamic region. Since the regulation of body temperature undoubtedly involves some sort of reciprocal excitation and inhibition to develop a set point (10), preferentially affecting one group of thermoregulatory neurons would alter the temperature at which the body is regulated.

In conclusion, 1) increases in the concentration of circulating $T_{3}$ cause an increase in activity and decrease in selected temperature, 2 ) injections of $T_{3}$ directly into the preoptic/anterior hypothalamic region cause a decrease in selected temperature and 3 ) in another study plasma $T_{3}$ concentration increases during cold acclimation (31). These observations are consistent with the hypothesis that $\mathrm{T}_{3}$ is directly involved in alterations of the selected temperature that occur following thermal acclimation in fish. 


\section{REFERENCES}

(1) Prosser, C. L. Temperature. In: Prosser, C. L. (Ed.) Comparative Animal Physiology. W. B. Sanders, Philadelphia, Pa. 3:362-420. 1973.

(2) Prosser, C. L. add Nelson, D. 0. The role of nervous systems in temperature adaptation of poikilotherms. Ann. Rev Physiol. 43:281-300.1980.

(3) Pye, V. I., Wieser, W. and Zech, M. The effects of seasonal and experimental temperature on the rates of oxidative phosphorylation of liver and muscle from winter tench (Iinca tinca). Comp. Biochem. Physiol. $54: 13-20$. 1976 .

(4) Johnson, P. V. and Roots, B. I. Brain fatty acids and temperature acclimation. Comp. Biochem. Physiol. $2: 303-309$. 1969 .

(5) Wodtke, E. Lipid adaptation in liver mitochondrial membranes of carp acclimated to different temperatures: Phospholipid composition, fatty acid pattern and cholesterol content. Biochimia et. Biophysica Acta. 529:280-291. 1978.

(6) Hazel, J. R. and Prosser, C. L. Molecular mechanisms of temperature compensation in poikilotherms. Physiol. Rev. 54:620-677. 1974 .

(7) Hazel, J. R. and Sellner, P. A. Fatty acid and sterol synthesis by hepatocytes of thermally acclimated rainbow trout (Salmo gairderi). ‥ Exp. Zool. 1979.

(8) Oshima, T., Sakaki, N., Wakayama, K., Watanabe, Z, and Nishimura, S. Biochemical studies on an extreme thermopile, Thermus thermophilus: Thermal stabilities of cell constituents and a bacteriophage. In: Zuber, H.(Ed.) Enzymes and proteins from thermophilic microorganisms. Basel, Switzerland: Birkhauser Verlag. pp. 317-331. 1976.

(9) DeVries, A. L. and Lin, Y. The role of glycoprotein anti-freezes in the survival of Antartic fishes. In: 
Llano, G. A.(Ed.) Adaptations within the Antartic ecosystems. Gulf Publishing. pp.439-458. 1977 .

(10) Hamme1, H. T. Phylogeny of regulatory mechanisms in temperature regulation. $\mathrm{J}$. Therm. Biol. 8:37-42. 1983.

(11) Brooks C. M. and Zoizumi, K. The hypothalamus and control of integrative processes. In: Montcastle, V. (Ed.) Medical Physiology. 14:923-947. 1980.

(12) Crawshaw, L. I. Comparitive physiology of vertebrate thermoregulation. Ann. Rev. Physiol. 42:473-491. 1980 .

(13) Myhre, K. and Hammel, H. T. Behavioral regulation of internal temperature in the lizard, Tiliqua scincoides. Am. J. Physiol. 217:1490-1495. 1969.

(14) Crawshaw, L. I. and Hamme1, H. T. Behavioral regulation of the internal temperature in the brown bullhead, Icthalarus nebulosus. Comp. Boichem. Physiol. A47:1490-1495. 1974.

(15) Nelson, D. 0. and Prosser, C. L. Effects of preoptic lesions on behavioral thermoregulation of Green sunfish, Lepomis cyamellus, and goldfish, Carassius auratus. J. Comp. Physiol. 129:193-197. 1979.

(16) Crawshaw, L.I., Moffet, B. P., Lemmons, D. E. and Downey, J. D. The evolutionary developement of vertebrate thermoregulation. American Scientist $69: 543-550$. 1981 .

(17) Crawshaw, L. I. and Hamme 1, T. H. Behavioral thermoregulation in two species of Antartic icefish. Life Sci. 10(I):1009-1020. 1971 .

(18) Bull, H. 0. Studies on coordinated responses in fish. J. Mar. Biol. Assoc. 21:1-27. 1939.

(19) Jarvaid, M. Y. and Anderson, J. M. Influence of starvation on selected temperature of some salmonids. J. Fish Res. Board Can. 24:1515-1519. 1967.

(20) Crawshaw, L. I. Attainment of the final thermal preferendum in brown bullheads acclimated to different temperatures. Comp. Biochem. Physiol. 52A:171-173. 1975. 
(21) Reeves, R. B. The interaction of body temperature and acid-base balance in ectothermic vertebrates. Ann.

Rev. Physiol. 39:559-586. 1977.

(22) Crawshaw, L. I. Low temperature dormancy in fish. Am. J. Physiol. 1984, in press.

(23) Crawshaw, L. I., Ackerman, R. A., White, F. M. and Heath, M. E. Metabolic and acid-base changes during selection of warmer water by cold acclimated fish. Am. J. Physiol. 242:R157-R161. 1982.

(24) Hulbert, A. J. The thyroid hormones: A thesis concerning their action. $\underline{J}$. Theor. Biol. 73:81-100. 1978 .

(25) Gorbman, A. Thyroid function and its control in fishes. In: Hoar, W. S. and Randall, D. (Eds.) Fish Physiology. Academic Press: New York, N. Y., pp. 241-274, 1969 .

(26) Eales, J. G. Thyroid functions in cyclostomes and fishes. In: Barrington, E. J.W. (Ed.) Hormones and Evolution. Academic Press: New York, N. Y., pp.341-436, 1979 .

(27) Gorbman, A., Dickoff, W. W., Vigna, S. R. and Ralph, C. L. The thyroid gland. In: Comparative Endocrinology. J. Wiley and Sons: New York, N. Y., pp.185-276, 1983.

(28) Fortune, P. Y. Effects of thiourea treatment on temperature selection and swimming behavior in Phoxinus phoxinus. Experimentia. 19:485-486. 1963.

(29) Reynolds, W. W., Casterlin, M. E. and Spielere, R. E. Thyroxine: Effect on behavioral thermoregulation in fishes. Can. ‥ Z001. 60:926-928. 1982.

(30) Crawshaw, L. I., Grahn, D. A. and Darling, D. S. The importance of plasma triodothyronine in the selection of cooler water by cold acclimated fish. (abstract) Fed. Proc., 1984, in press.

(31) Peter, R. E. and Gill, V. E. A stereotaxic atlas and technique for forebrain nuclei of the goldfish, Carassius auratus. ‥ Comp. Neur. 159:69-102.1976.

(32) Stevens, E. D. The evolution of endothermy. ‥ Theor. Biol. 38:597-611. 1973. 